\title{
A Square Dancing Celebrity
}

\author{
Peifeng Wang
}

\section{Interview with Mr. LZ's Parents}

LZ, male, born in 1983. The only child in his family. Level IV intellectual disability. Studied in a regular class in the Shanghai Jiangwan Junior High School and graduated in 1999. Enrolled in a subdistrict Sunshine Home in Shanghai in 2005. Transferred to another subdistrict Sunshine Home in the district in 2010.

Interviewees: LZ's parents

Interviewer and writer: Peifeng Wang

Interview dates: November 13, 2016 and January 3, 2017

Interview place: LZ's home

\section{Born Amid Hardships}

Q: How did you meet?

LZ's mother: We are both senior high school graduates of 1966-1968. After graduating from high school in 1968, my husband was sent down to work on a farm in Dedu County, currently Wudalianchi City, in Heilongjiang Province in 1969. I was sent down to a farm in Nenjiang Region (currently being incorporated into Qiqihar City) in the province a year later, that is, in 1970. We returned to Shanghai a decade later. Our classmates introduced us to each other in 1980. Thanks to a similar experience in Heilongjiang Province, we got along well and (fell in love) smoothly. We got married in 1982. We just started to work and were busy. We were eager to learn more to serve the country better.

P. Wang $(\bowtie)$

East China Normal University, 3663 Zhongshan Bei Ro, Shanghai 200062, China

(C) The Author(s) 2020

W. P. Alford et al. (eds.), An Oral History of the Special Olympics

in China Volume 2, Economy and Social Inclusion,

https://doi.org/10.1007/978-981-15-5128-4_5 
I majored in finance in a secondary technical school. As a result, the post in the Finance Department was in my field. On the contrary, my husband had done a variety of jobs before he served as a teacher and was selected to work in the Finance Department. I gave birth to LZ in 1983. I was at an advanced maternal age. I was sent down to work on the farm when I was 22 . We got married at 32 and had a baby at 33 .

You should know that life was not easy on the farm. My health may have deteriorated there. After returning to Shanghai, I had to work hard to make a living. Being underpaid, I could hardly make ends meet and restore my full health. At the seventh month of pregnancy, I could faintly hear the baby's heartbeat. I went to the designated hospital, the First Maternity and Infant Hospital, and found that the baby's heartbeat was slow. I thought that may affect LZ's brain development. I inhaled oxygen and the baby's heartbeat became normal. As a result, I no longer worried about the issue and worked as hard as I did before. I would never ask for leave. The Finance Department was busy. We focused on work and cared little about our state of health.

I gave birth to LZ in January 1983. It was actually a normal delivery. Prepotency was not publicized at that time. Babies were delivered naturally. I was at an advanced maternal age and exhausted. Nonetheless, the doctor encouraged me to have a natural birth. I was in great pain in the process. It might have also affected the baby. My water broke before labor started. As a result, LZ lacked oxygen during his birth. He did not cry the moment he was born. The doctor slapped his back and he started to cry. The doctor was relieved. LZ behaved normally after he was born. I stayed at my mother's during postpartum confinement. LZ grew up gradually and learned to talk later than other kids did.

My mother reassured me that it was normal for baby boys to learn to talk late. We did not pay attention to that, either. Both of us were inexperienced. LZ was our first and only child. No one could take care of LZ. I have three siblings. So does my husband. Our parents were too busy to give us a hand. We had to work hard during the day. As a result, LZ was babysat by our neighbors, a couple in their fifties or sixties. They kept taking care of him until we moved when LZ was in Grade Three. They treated LZ well. We did not notice anything abnormal about LZ. He talked little but could speak Shanghainese fluently.

LZ's mother: He went to school at school age. Learning to talk late, he barely spoke at the nursery. The teacher might ask him whether he had pooped. If not, he would be required to poop in the bathroom. He did not cooperate and cried violently. He was hard to handle. Nor did he have regular bowel movements or was capable of self-control. He could not remember homework and reacted slowly in kindergarten. LZ had a tough time from the nursery to the elementary school.

Q: What about LZ's state of health in his school time?

LZ's mother: He was healthy.

Q: He didn't get sick easily when he was small, did he?

LZ's mother: That is true. It was easy to look after LZ when he was little. 


\section{Confronting Reality and Finding Out the Truth}

Q: When did you suspect that LZ may have an intellectual disability (hereinafter ID)?

LZ's mother: His teacher from kindergarten remarked that LZ could hardly string two coherent words together. His brain was not developed as well as his peers. Two of my close friends also mentioned that LZ might be reacting slower. Moreover, he learned to talk late. All of these pieces of evidence indicated that LZ had an ID. We were not highly sociable at that time. We thought the condition would improve after LZ grew up. Our parents also thought that boys (learn to talk) late. (All will be well).

We started to notice that something was wrong with LZ when he enrolled in elementary school. LZ was able to read and write Chinese characters. He could also memorize math formulas. However, he could not solve problems requiring logical thinking such as word problems and mixed basic arithmetic operations. For example, he could not work out a formula for a word problem. I tutored him at night. Still, he could not do that. I was exhausted and scolded or beat him.

LZ's father: He barely passed Grade One and Grade Two. He fell behind obviously in Grade Three. I noticed that he worked hard. Other kids might be naughty and not (perform well). LZ could get down studying. However, he could not think logically and solve problems. After a long while, my wife got impatient and scolded him. However, it was useless. With great reluctance, I started to suspect that LZ had issues here (pointed at his head).

Q: You realized that $\mathrm{LZ}$ may be with ID?

LZ's mother: Yes. LZ performed poorly in arithmetic. The teaching process was much slower back then. Students made progress step by step. LZ could not solve word problems in Grade Three. Nor did he perform well in the test required in order to transfer him.

LZ's father: I was the first to suggest that he be examined.

LZ's mother: My husband suggested going to the hospital. I agreed. We hadhim checked twice. The first time was in 1994 when he was in Grade Four. He stayed at my mother's, which was located near the Children's Hospital of Shanghai.

LZ's father: It would be troublesome if something was wrong with this part (pointed at his head). I was unwilling and restless with anxiety to think of the issue. However, I had to face it and find out the truth via scientific means.

Q: LZ's case was confirmed in 1994, wasn't it?

LZ's mother: That is correct. He was examined at the Department of Children's Healthcare at the Children's Hospital of Shanghai. On seeing the result, the pediatrician remarked that what LZ achieved was below the normal value. Here it is (shows the result of the Wechsler Individual Achievement Test). LZ got 44 points on average. He got 55 points in language and 50 in manual dexterity. Nonetheless, the pediatrician also mentioned that it was too early to reach a conclusion. LZ was little. He might go backward and be slow to understand things. We were asked to talk more to him and teach him patiently to help him grow faster.

Q: Did you see doctors far and near after the examination? 
LZ's mother: Of course. Some doctors commented that LZ could not learn due to the attention-deficit hyperactivity disorder. LZ took a variety of brain supplements such as Naolijian. However, he had issues here (pointed at her head). These supplements did not work.

Q: Did you realize that LZ might be with ID?

LZ's mother: You may say so. We were embarrassed and tried to solve the issue by ourselves. We didn't want to accept the results and were unwilling to tell others about it.

LZ was in Grade Five in 1995 . He fell behind even more along with more courses he had to take. His math teacher told my husband that LZ might affect the class's enrollment rate as a whole. She wanted to take LZ to the hospital to test his IQ so that she could explain the situation to her boss and exclude LZ's performance in her assessment. That was also what my husband wanted. We had done it the year before. We wondered whether the situation would improve a year later. As a result, accompanied by the teacher, my husband took LZ to Xinhua Hospital.

LZ's father: LZ fell behind apparently in math. In fact, he worked hard and was well behaved while the teacher paid more attention to him. However, the results remained unsatisfactory.

In comparison, his performance was acceptable with respect to English and Chinese. LZ managed to move up to the next grade. Some students failed to pass exams and stayed down. The math teacher tutored LZ because she had dealt with students reacting slowly. She worried that LZ might affect the class's total enrollment rate. After all, it was the criterion applied to assessing a teacher's performance.

I told her that LZ had been tested the year before. The result showed that he reacted slowly. I wished that it was because he grew up slower than his peers did. In the current case, I had to ask the teacher to be more patient with LZ. She thought that we were reasonable. Some parents might not cooperate. She didn't know that I was (open-minded) and had already taken the initiative to have LZ tested.

I also told her that it was too early to jump to a conclusion. The doctor remarked that the test result was for reference only. She commented that it was rare to see parents as reasonable as me. She was glad that I actively cooperated with her. In fact, both of us wanted to find out the truth. She suggested that we go to the hospital together to have LZ tested. I was happy to. The result from the second test might be more convincing than that of the first one. Moreover, we were to go to the Xinhua Hospital, which was renowned for the treatment of pediatric diseases.

Children could have IQ tests on certain days there. I could not recall the specific date. A female pediatric specialist wearing glasses asked me about LZ's condition. Then she took LZ into a room to test him. We waited outside.

After the test was done, the specialist talked with me alone. She was nice and wondered whether I took LZ to be tested voluntarily or under the requirement of the teacher.

I told her that both the teacher and I wanted to find out LZ's state of health. The specialist understood me. She said that many (parents) were against taking their kids to be tested at the hospital. They complained that some teachers have children tested for their own purposes. Some teachers even took children to the hospital without the 
parents. I explained that I was okay with the situation and just wanted to learn about LZ's state of health.

Hearing that, she told me that something might be abnormal about LZ's brain development. Nonetheless, the symptoms were mild. I mentioned that LZ was in Grade Four. She commented that our family must have worked hard jointly so that LZ could go this far. She said that she would explain the situation to the teacher separately.

I asked for advice. She prescribed traditional Chinese medicine benefiting brain function and asked me to have LZ examined a year later. The medicine cost as much as over 1,000 yuan per month or half a month. I can't remember clearly. We could only earn over 100 yuan per month. We were under great pressure.

LZ's mother: A course of the treatment lasted for about 3 months. We could not afford that.

LZ's father: The cost was 1,000 yuan for 3 months of medicine. LZ might have taken the medicine for a whole year (thinking back).

LZ's mother: That is true. We had (little) savings. I used up the money my mother had given me.

LZ's father: LZ accepted a course of the treatment and was tested again.

LZ's mother: The medicine worked slightly.

LZ's father: Slightly.

LZ's mother: The improvement was not obvious.

Q: Is there any relative in your families that is with ID?

LZ's mother: No.

Q: For generations?

LZ's father: No one in our families suffers from it.

LZ's mother: It might be because we have overworked or suffered from malnutrition when being sent down to work in Heilongjiang Province. However, we have ensured sufficient nutrition for LZ.

Q: How did you handle it after knowing the truth?

LZ's mother: We were anxious but had no solution. Back then, we would be off duty after six o'clock in the evening.

LZ's father: We depended completely on ourselves.

LZ's mother: My father-in-law had passed away long time ago. My mother-in-law and my parents were too old to (take care of) LZ.

\section{Busy Working Hard at School}

LZ's mother: On seeing the result of LZ's IQ test, my husband suggested enrolling LZ in a special school. Miyun School, a special school, had been established in this district. My husband asked around and was informed that the school only admitted students at Grade Three or lower. We had no other solution but enrolling LZ in a regular class and leaving things to chance.

Q: What subjects were available in the elementary school? 
LZ's mother: They may have included Chinese, math, English, PE, music, history, and geography. They used to be easier and less complicated in comparison with those given now. LZ could still tell what he has learned from geography courses.

Q: Which one was his favorite?

LZ's mother: English. He was also good at Chinese.

LZ's father: Memorization is (significant) to learn English well.

Q: Was LZ good at English?

LZ's mother: His performance was satisfactory with respect to English. I focused on tutoring him math.

Q: Was math the most challenging subject for LZ?

LZ's mother: Math it is. He has performed increasingly poor in math.

LZ's father: He could not think logically.

Q: What was taught at math courses?

LZ's mother: Basic arithmetic operations.

$\mathrm{Q}$ : Did the teacher teaching math treat LZ as well she had done after accompanying you to have LZ tested at the hospital?

LZ's mother: She was under less pressure and pressed less hard on LZ. However, LZ was a point from passing the math exam to be admitted to the middle school. He had to stay down and repeat Grade Five.

LZ's father: LZ is with ID. The teacher might go (too far) to fuss about one point. LZ used to get along well with his classmates. After he stayed down, he was known as the student who stayed back. It would hurt a kid even if it was merely one point.

LZ's mother: LZ could not go up to the next grade if he only got 59 points in the exam. The headmaster asked to let LZ stay down. I have come around. After all, LZ failed to lay a solid foundation for further learning.

Q: What about his Chinese?

LZ's mother: Just so-so. LZ could not write a composition independently. He would pass the exam by memorizing one.

$\mathrm{Q}$ : One has to understand the topic before writing a composition. Was it hard for LZ to comprehend the topic?

LZ's mother: Of course. Only 30-40\% of the content at most would meet the requirement.

Q: Did you mean that he could not complete the composition or digress from the topic?

LZ's mother: He could hardly stick to the topic.

Q: Did he stray from the point easily when writing a composition?

LZ's father: His composition was illogical.

Q: What about vocabulary and reading comprehension?

LZ's mother: He could do word dictation and complete reading comprehension. However, he was impatient to listen to you reading a book from cover to cover. He liked recitation but couldn't write a composition.

Q: Was the handwork course available at elementary school? Would LZ perform better at the course?

LZ's mother: Not at all.

LZ's father: He might bring the homework home and my wife gave him a hand. 
LZ's mother: Exactly. LZ could only complete a rough handwork and I helped him to process it into a delicate one.

$\mathrm{Q}$ : Did he perform well in any of music, PE, and drawing courses?

LZ's mother: His performance was acceptable but inferior in comparison with that of normal students. He performed worse in PE because he spent most of the time in finishing his homework.

Q: Did you merely tutor LZ as a way to accompany him at night?

LZ's mother: We had to. He could not follow teachers in class. We had to teach him again at home after dinner. He probably sat by the desk steadily with a pen in his hand. He (seemed to be) studying but actually just dawdled. I tutored him math and my husband Chinese. We did not go to bed until he completed all of the homework. He was cooperative and tractable and memorized content he was required to.

Q: Did you train LZ specially when he was medicated?

LZ's mother: No, we merely tutored him. He might take a break on Saturday or Sunday. We would accompany him to go to the park to exercise when the weather was good during spring and fall.

LZ's father: He was not pressured and had to do a small amount of homework. Back then, students would merely need to pay attention in class to perform well in exams. They did not go to various tutoring institutions.

Q: Did LZ like to play?

LZ's mother: He loved to when he was little. However, he had to do homework first.

Q: What would LZ do after having dinner and completing his homework?

LZ's mother: He would read. We also bought him toys. However, he didn't have time for them. I recall that he spent all his time on doing homework while his peers played after doing homework.

Q: Did LZ ever agonize about that and want to give up?

LZ's mother: No, he didn't dare.

LZ's father: He suffered internally. When my wife scolded LZ, I thought that I had been way naughtier in my childhood. On the contrary, LZ worked hard. Why couldn't he perform well? As a result, I put forward first the suggestion to have him examined. It was useless to punish LZ if we didn't know the reason of his poor performance.

Q: Did LZ work hard because he realized that he performed worse than his peers did or merely because he was asked to?

LZ's mother: He did realize that. He may have been bullied, but he didn't tell anyone. For example, he would not tell us even if he was hurt (at school).

LZ's father: In fact, it was common among boys.

LZ's mother: He was (aware of) that (but) could not answer back. He would merely take it if he was called stupid. LZ never responds even if we talk tough. Nonetheless, he will talk to me if anything occurs at the Sunshine Home. He does not communicate with his father much. Nor would he obey his father's instructions sometimes. I told him that he should not put up with everything alone. I asked him to communicate with parents and teachers in time. Being the class monitor at the Sunshine Home, he needs to report problems in the class to teachers and get along well with classmates. 
Q: What about his performance after repeating Grade Five?

LZ's mother: The situation changed slightly. He could barely write an eligible composition and perform moderately in Chinese. Regarding math, I asked him to solve all types of word problems and memorize them. It was the only solution. He has a good memory. That is how he could get 80 points in English. In the end, he got 67 in the math exam and enrolled in the Shanghai Jiangwan Junior High School. It was possible that some word problems he had memorized were exact test questions.

\section{Finishing Middle School Smoothly, but Discouraged at Vocational School}

LZ's father: Many students might fail the law and morality course in middle school. However, LZ could memorize the whole textbook, which impressed his teacher. He could also memorize a speech rapidly. His good memory could at least mitigate his shortcomings in other aspects.

LZ's mother: He met a nice teacher in Shanghai Jiangwan Junior High School. The teacher would teach him patiently and ask other students to treat LZ well. The class director treated LZ better. We explained LZ's condition and entrusted LZ to him. He felt pity for us. I gave birth to LZ at an advanced maternal age. He was honest and understood our difficulties and paid special attention to LZ.

Q: Which subject did the class director teach?

LZ's mother: He taught politics.

LZ's father: That is true. He just started to work at that time.

LZ's mother: We still think about him now.

Q: Was LZ interested in the politics course because of him?

LZ's mother: He could basically recite content taught in the course fluently. The teacher liked him. LZ took care of others, which (surprised) the teacher.

Q: Did LZ study in a regular class in middle school?

LZ's mother: He always studied in a regular class. He was also tutored by teachers after school. As a result, he was able to (keep up) and perform (moderately).

We may have worried less if he had enrolled in a special school at first. However, LZ could not learn so much. At the special school, teachers would hardly teach anything. They merely (make do) and organize students to do some handwork. I have been a teacher at the CAPIDR ${ }^{1}$ for over a decade. Students graduated from the special school differ greatly from those graduated from the regular school. For example, students who graduated from Miyun School were less educated. They could not do basic arithmetic operations, causing great inconvenience to them in their daily life. The school has been irresponsible.

Q: Except for academic achievements, do students studying in the regular class also have an advantage in respect of social communications?

\footnotetext{
${ }^{1}$ Association of Persons with Intellectual Disabilities and their Relatives.
} 
LZ's mother: Certainly. Students from the two types of schools behave completely different when communicating with others.

LZ's father: But the academic pressure is also huge in a regular school.

LZ's mother: LZ might be pressed hard regarding his studies. The silver lining is that it is easier for him to fit into society after graduation.

Q: How did LZ get along with his classmates at school?

LZ's mother: Well, he made several friends in his class and did homework and played games with neighborhood kids.

Q: Did LZ have any close friends?

LZ's mother: Yes, several honest boys. We have kept a close eye on him. On one hand, he had to do a mountain of homework. On the other hand, he didn't have any pocket money.

Q: LZ would rarely have conflicts with others, right?

LZ's mother: He would never take the initiative to have words with others. It was the other way around. I was fully aware of that. In that case, whenever some students blamed LZ for a quarrel, the teacher would assert that it was their fault.

Q: How many years did it take for LZ to finish middle school?

LZ's mother: He spent 5 years in elementary school and 4 years in the preparatory class in middle school. ${ }^{2}$

LZ's father: Back then, we were advised by the teacher to not apply for a (Disability) Certificate for LZ, which would be unfavorable for LZ. We did it later. It was all right that LZ didn't go to a college. He could still learn cooking and make a living.

LZ's mother: Previously, people like LZ were looked down upon. Currently, the situation has changed along with social progress.

Q: Did LZ learn cooking after graduating from the middle school?

LZ's mother: In fact, LZ only got a Middle School (Diploma). Later on, he enrolled in Shanghai Chunshen Tourism Secondary Vocational School.

LZ's father: His performance was too poor to enroll in high school. (The teacher) persuaded us to apply to this vocational school. LZ would certainly (do that) because he had no other option.

Q: Did LZ pass the entrance exam and enroll in the vocational school?

LZ's mother: Of course.

Q: Is Shanghai Chunshen Tourism Secondary Vocational School a regular school or a special one?

LZ's father: It is a regular school admitting students with poor performance.

LZ's mother: The school has also admitted deaf students. LZ met the minimum age requirement to go to the vocational school but was weaker in his performance. A chef needs to chop vegetables. We were asked to prepare two kitchen knives to let LZ practice cutting potatoes and meat into shreds. However, LZ failed and cut his finger. Being not interested in it, he skipped school several times and quit.

\footnotetext{
${ }^{2}$ The 9-year compulsory education system is the "five-four system" in Shanghai. Students are taught in elementary school for 5 years and 4 years in middle school. Grades in the middle school include the Preparatory Grade, Grade One, Grade Two, and Grade Three.
} 
Q: Did he tell you about him skipping school?

LZ's mother: He had no other place to go but my younger sister-in-law's, which was near the school. She asked LZ why school was over (so early). The teacher visited us several days later and said that LZ didn't go to school for a week. The head teacher told me that the school did not suit LZ. He could not continue studying there.

We agreed. It would be useless to pay the tuition while LZ escapes school. He could not do the assigned homework. We were fully aware that LZ had performed well to go this far.

LZ's father: We have to accept reality. The education system is a pyramid. The higher it is, the fewer people there will be. It is hard for LZ to go further. LZ has performed poorly with respect to manual work. After discussion, we agreed to withdraw LZ from the school. The tuition was 1,800 yuan for each semester. We paid for two semesters. LZ skipped school within the first month of the second semester. We wasted the money.

Q: What was your plan at that time?

LZ's father: I had no other option under the circumstances.

LZ's mother: LZ did not make any progress after a semester. He could not (go up to the next grade). He didn't want to be there anymore. He had insisted on studying at school when he was little.

Q: Did LZ himself say that he would never go to school again?

LZ's mother: That is correct. He told us that he would rather die than go there.

\section{Learned Basic Skills to Take Care of Himself}

Q: When did LZ start to look after himself, meaning washing up and brushing teeth?

LZ's mother: He could do that when he was little. The result might not be satisfactory at first. Nonetheless, LZ has made progress gradually. He was able to take a bath independently after he was 10 . I had bathed him before that.

Q: LZ is with ID. Will you train him to take care of himself independently?

LZ's mother: We have taught him to take care of himself late. To be honest, it takes time for LZ to do these things by himself. My husband and I were busy going to work. I worked around the Bund while my husband worked near Xieqiao and Dapuqiao. The traffic was bad. The metro was not built yet. I needed to transfer twice and my husband had to transfer three times. It was exhausting. I would rather do it by myself than teach LZ. After all, I had to clean up in the end. I had no time to teach him patiently. After retirement, I can take it easier to teach him.

Q: You were busy. As a result, LZ was not trained to take care of himself in daily life. Is that correct?

LZ's mother: You may say so. I lowered my expectations. LZ could wash up roughly. I had no time to correct him. I would ask him to wash up carefully on Sunday. Currently, he is shy when I offer to scrub his back when he takes a bath. He refuses and does that all by himself. I further offer to wash his feet. I know that he 
cannot wash his feet clean. He also turns me down. I have to let it go. I wonder what LZ would be able todo if he lived independently. He told me that he was independent. However, it is obvious that he is not capable of taking care of himself.

Q: Have you started to train him especially after retirement?

LZ's mother: Yes. He doesn't dare turn on the gas stove. We have to do it for him. He can take a bath independently. He can also (use) a rice cooker. He cannot cook.

Q: Is he capable of washing and cutting vegetables?

LZ's mother: Absolutely. He is more careful than I am. He pays attention to personal hygiene and washes his hands. He strives to keep healthy and develop certain recipes if he feels uncomfortable. He has learned that from his father.

Q: Do you have different opinions on LZ's development?

LZ's mother: No.

Q: Did you when LZ was little?

LZ's father: I had to find a reason for LZ's poor performance when LZ was little.

LZ's mother: I required LZ to complete his homework and my husband asked me not to beat $\mathrm{LZ}$.

LZ's father: I could find specific solutions after I found out the reason.

LZ's mother: We have taken steps gradually. I do not think we have made many detours.

Q: You have worked in harmony, right?

LZ's mother: That is true.

LZ's father: We just (found out the truth) late.

\section{Registering in the Community and Being Assigned to a Company due to the Disability Certificate}

Q: Did LZ stay at home after withdrawing from the vocational school?

LZ's mother: He worked at Linong after withdrawal. He was 19 at that time.

Q: What is Linong?

LZ's mother: It means the community. He did nothing at home and became plumper day by day. I will show you a photo later.

LZ's father: I had never sorted help from the subdistrict office. However, I had to for LZ's sake. I explained LZ's condition. An officer named Wang, who was in charge, was nice and asked me to write and submit an application first. Then he could (accept and handle the issue).

LZ's mother: He advised us to check and prepare the needed materials. LZ could not do what normal kids do. As such, it was suggested that I (figure out ways to) apply for the Disability Certificate first. It had never occurred to us to apply for the certificate.

Q: Haven't you ever thought about applying for the Disability Certificate for LZ from the time you found out that he was with ID to his graduation from middle school? 
LZ's mother: We never thought about it. We felt embarrassed. We have strived to help LZ to grow up as a normal kid and fit into society.

LZ's father: The disabled have to obtain the Disability Certificate to enjoy preferential policies. It is useless to reason about that.

LZ's mother: We were asked to bring LZ to be tested at Shanghai Hongkou District Mental Health Center on Wednesdays or Thursdays. A mental health center was established in every district. The disabled are identified there. It was 2001 or 2002. Officer Wang told me that LZ could enjoy preferential policies if he obtained the Disability Certificate. He advised me to exaggerate LZ's condition to obtain the certificate smoothly.

Instead, I told LZ at home to answer all the questions he could. In the examination, we realized that $\mathrm{LZ}$ did not suffer from issues such as color blindness. He could also complete basic arithmetic operations. The only issue was that it was hard for him to give direct answers.

The old doctor told me that the situation was complicated. LZ could do arithmetic operations. He can either be regarded as a person with ID or not.

I told him that LZ was absolutely with ID. I implored him to help LZ to obtain the certificate. My husband and I are older and will be retired soon. LZ, being with ID, could not go to school. We have to make plans for him. We would never come here if LZ could go to school as normal kids do.

The doctor felt pity for us. He said that he would consider it and asked us to wait for news at home. I begged him to lower LZ's scores.

Later on, LZ was assessed to meet (disability standards). About 2 weeks later, I was informed by a subdistrict officer that LZ could come over and take away his Disability Certificate. I went there and found that LZ was assessed to be with mild ID. I was relieved that LZ was at least recognized to officially be with ID. People with mild ID did not obtain any allowance at that time. Only those with moderate and severe ID would receive an allowance of about 300 yuan or 400 yuan per month. I complained that my efforts were in vain. Well, I explained to my husband that the stamped result has been rigid and hard-and-fast.

After a while, a subdistrict officer asked me whether LZ obtained the Disability Certificate. I told him that we were in a dilemma. LZ could not enjoy any preferential policy even after obtaining the Disability Certificate. He mentioned that LZ could obtain subsidies from the subdistrict office if he works in the community. A new property management company just replaced the former one after the serving term expired. LZ could work there as a cleaner. I agreed. LZ got chubby at home. He could work and practice in reality. The officer wondered whether LZ could endure the hardships. I assured him that he could. It was not complicated to be a cleaner. He explained that the payment was not much. The property management company paid 100 yuan while the subdistrict office covered 150 yuan. The payment totaled 250 yuan (he laughed at the amount because the number 250 means a stupid person in Chinese). I said it was not a problem. After all, LZ could work as a way of (physical exercise), otherwise he would be idle at home and come down with diseases such as a fatty liver at a young age. LZ worked hard. He cleaned the street as carefully as he did at home. Then he would have lunch. He was praised for his excellent performance. 
After over a year, I discussed with my husband that now that LZ worked and was paid regularly, he could enter the social insurance scheme. We consulted an officer named Cao from the subdistrict DPF. He learned that LZ was with mild ID and calmed us down. He said that LZ was only 24 years old. A new policy would be released by the federation to benefit people who had mild ID and (who) could not receive any allowance. I listened and left him with our contact information.

The new policy might be released after the Spring Festival. Major companies must offer certain posts for people with mild disabilities. If they could not set these posts, people with mild disabilities could be assigned to them and get paid but not need to work. LZ was lucky to be among the first batch of disabled people assigned to major companies. Later on, LZ ceased to work as a cleaner. On one hand, it was exhausting. On the other hand, the property management company was restructured. He has been assigned to a company from then on.

\section{Life from Bitter to Sweet after Joining in the Special Olympics Movement}

LZ's mother: After LZ was assigned to a company, the subdistrict DPF went through an election after expiration of a term of office. The former Chairman and Vice Chairman of the Subdistrict CAPIDR were in their seventies. Younger persons were wanted there to run affairs. I had joined the association recently. As a result, I was elected.

Q: How did you join the association?

LZ's mother: The DPF has five affiliated associations, that is, the Association of the Blind, the Association of the Deaf and Hard of Hearing, the Association of Persons with Psychiatric Disability and their Relatives, the Association of People with Physical Disabilities, and the CAPIDR. The disabled persons participate personally in the Association of the Blind, the Association of the Deaf and Hard of Hearing, and the Association of People with Physical Disabilities correspondingly. Persons with ID must have guardians to participate in the CAPIDR. I joined the association as LZ's guardian.

Q: The subdistrict office sets up the Subdistrict CAPIDR but does not force people to participate. Is that correct?

LZ's mother: Of course. The associations have been managed in a hierarchy system. The disabled people play a part in activities held at the subdistrict level, the district level, and the city level step by step.

I was selected to be in charge of the Subdistrict CAPIDR in 2002. I would attend meetings at the district level and the city level first. Then I would convey what I heard to the district level. Hongkou District used to be divided into ten subdistricts. The number is reduced to eight now. Each association has one Chairman and one Vice Chairman. We gathered together to figure out new ways to hold activities in these associations. The Chairman of the Hongkou District CAPIDR was called Wang. The Vice Chairman was called Zhen Ni. He used to be an officer at the Hongkou District 
Commission for Discipline Inspection. Under the guidance of $\mathrm{Mr}$. Ni, our activities were famous in a limited scope in 2005. Mr. Ni was reported in newspapers in 2006. Shanghai hosted the Special Olympics World Summer Games in 2007. This was LZ (pointed at a photo) in 2006.

Mr. Ni said that kids with ID have been kept at home. He investigated the number of people with ID in Hongkou District. There were over 100 in our subdistrict. It was very beneficial for them to join outdoor activities. They could not fit into society if they stayed at home. He suggested establishing a choir. LZ was among the first batch of members in the choir.

Q: Were people with ID organized to sing?

LZ's mother: Each of us took a lead to teach our kids to sing and gathered them to sing in the choir. However, these kids could not carry a tune. I noticed that few children with ID have been good at singing. Neither Mr. Ni nor the rest of us had the confidence to continue the choir after two activities. The children were also reluctant to sing.

Under these circumstances, Mr. Ni suggested we organize these children to play the waist drum as a way of intellectual development. It has been common to see senior people playing the waist drum. As a result, a waist drum team has been set up for people with ID in Hongkou District. At the beginning, we recruited 18 children with ID. LZ was one of them. A retired lady from Ouyang Subdistrict, who was a member of a waist drum team, was invited to teach them. The team used to practice at Miyun School on weekends. They might learn something today and forget most of it the next day. Nonetheless, they kept learning and practicing.

$\mathrm{Q}$ : Was LZ interested in the activity?

LZ's mother: He could not play the waist drum at first. I accompanied him there by bus. After a while, he became interested in it. Having mild ID, he could understand the teacher better and learn how to play the waist drum. Then he would teach other members. He has practiced every day and made (progress) gradually. The activity was recognized at the district level. After the team finished rehearsing a complete program, we were organized to attend a municipal meeting, during which the team became famous in Shanghai. Being supported by municipal leaders, we have been more confident in continuing organizing the activity. Parents have brought their children to participate, too.

Mr. Ni also asked me to play the waist drum and teach others. He joined us as well. We, Chairman and Vice Chairman of the Subdistrict CAPIDR, spent a lot of effort to learn to play the waist drum. Then we taught others. LZ has become more confident after playing the waist drum for a while. He has outperformed others in imitation. After participating in the activity, he has made obvious progress and has been capable of communicating with others better. He was the first to join the team under the instruction of $\mathrm{Mr}$. $\mathrm{Ni}$.

(Holding a photo) This is Mr. Ni, the Vice Chairman of the Hongkou District CAPIDR. He led us in the activities. He said, "Lin, we should be engaged in this field for several years together." I followed him from 2002 until now. The waist drum team established by Mr. Ni has held activities on weekends. 
It became famous in 2005. Back then, it was already known that Shanghai won the bid to host the 2007 Special Olympics World Summer Games. As a result, we started to prepare. Each of us would learn a set of moves and develop a new waist drum program for people with ID exclusively.

Our original intention to organize the waist drum team was to encourage children with ID to do exercise and enjoy themselves. After the team became famous, we paid more attention to running it well. (Pointing at a photo) This is Ms. Zhou teaching the waist drum team. She was the mother of a team member from Jiaxing Subdistrict. She taught LZ.

LZ: Xiaodong Yu.

LZ's mother: Her son had cerebral palsy. LZ and her son are good friends. Shanghai was to host the 2007 Special Olympics World Summer Games. However, none of us was good at English. Ms. Zhou volunteered to teach us. She also tutored LZ in English. Her son can speak German and French. Mr. Ni, who is fully aware that Ms. Zhou is (competent), recommended her to be the Special Olympics Global Ambassador. Naturally, Ms. Zhou has become one of the Special Olympics Global Ambassadors. ${ }^{3}$

Being the family leader, she thinks she is obligated to take the lead to launch the Special Olympics Oral History project in the district. She has collected various materials. We could only provide limited information. You could turn to her for anything you need.

She also told me to be at ease during the interview. She has helped me a lot. We get along well with each other. She volunteered to teach children with ID English and dancing. LZ has learned English and dancing from her.

LZ: Don't forget about the Special Olympics Athlete Leadership program.

LZ's mother: Exactly.

Q: Is LZ also an athlete leader?

LZ's mother: That's true. A boy and a girl with ID were selected in Hongkou District to participate in the Special Olympics Athlete Leadership program to be prepared for the 2007 Special Olympics World Summer Games. LZ was lucky and (selected) by playing the waist drum. I must thank (those that have devoted themselves) to training children with ID such as LZ.

At that time, all work was centered on the 2007 Special Olympics World Summer Games in Shanghai. Athlete leaders needed to rehearse a dance to appear on the stage of the 2007 Special Olympics World Summer Games. This is LZ (pointing at a photo) dancing. He has developed various interests gradually. LZ became interested in dancing from then on. He was fully aware that he wanted to dance.

LZ: (pointing at a photo) This is dancing.

LZ's mother: They danced together.

LZ: The badge of the athlete leader.

\footnotetext{
${ }^{3}$ The official title is "the Special Olympics East Asian Family Leader for the 2007 Special Olympics World Summer Games in Shanghai”.
} 
LZ's mother: He would learn from senior citizens to dance in the community park. He is a big fan. I am not. He has learned and remembered moves. It is really helpful. He is confident in doing that.

We started to participate in the Special Olympics movement since 2007. LZ has participated in all of these activities. Regarding sports he is not good at such as table tennis and basketball, he would practice at home. (Showing a trophy) I urged LZ to participate in an activity held in the community and he won this trophy. Whenever there was an activity, he would ask me to join. I would not. Instead, I took LZ there. He won first prize in a dance competition and became famous in the community.

LZ: Mongolian folk dance.

LZ's mother: (holding a photo) LZ performed a Mongolian folk dance (covers her face and laughs). He got the costume as a gift. (Continues viewing photos) This is Bingbing Li. Seeing our waist drum team, she contacted us in private and donated over 80,000 yuan.

LZ would participate in all the activities he was capable of. He likes to do exercises. Once, Mr. Ni was selected as a municipal advanced individual and went to Beijing to accept the prize. He took LZ with him.

Q: Which Special Olympics activities did LZ participate in?

LZ's mother: LZ has participated in a variety of games such as running, basketball, and unified running.

LZ: Sorry (brought a box of medals).

LZ's mother: LZ won these medals by participating in (numerous) games. This one is the gold medal for an abacus and mental arithmetic competition. This is from a unified running event. This is from the games of the disabled persons.

LZ: Don't forget rhythmic gymnastics.

LZ's mother: Sure. He won a silver medal for that.

Q: LZ won so many medals, didn't he?

LZ's mother: That is true. LZ has sorted them all by himself. (Holding a medal) LZ won the gold medal from the unified running game in 2014. He won a silver one this year (chortling). He was lucky in the game in 2014. The fastest team broke the rules and had a fall. As a result, LZ and his team overtook them and won.

Q: Has LZ been trained to participate in games such as dancing or unified running?

LZ's mother: Of course.

Q: Are there any professionals to guide them?

LZ's mother: The professional teachers usually undertake certain games. Next, they pick eligible persons. For example, if ten players are needed in a game, two extra players will be selected as substitutes. Things are (arranged) in advance. All of these players will be notified a month earlier, because they needed to be trained in a certain place. Then they practice and receive coaching.

$\mathrm{Q}$ : Is the training program launched punctually every day?

LZ's mother: Players are coached by professionals at first. Then, they (practice) according to requirements. It is not easy. Some children's feet were worn out. After a while, they were able to practice with high proficiency.

Q: Did LZ ever show reluctance under these circumstances? 
LZ's mother: LZ is eager to (play a part). He never even flinches. On the contrary, he is afraid that he may be rejected. For example, tall persons have been selected to play horse. LZ did not fit. I told him to keep practicing. He was fully aware of that. Four men and four women were selected to participate in basketball shooting. LZ was not chosen. He knows well that he has been weak in the game. He is also aware that he may get a chance next year. He engages in activities actively. All of these people are aware that it is beneficial to do exercises.

Q: Have players gone to places outside Shanghai to participate in Special Olympics Games?

LZ's mother: Correct. But LZ hasn't. These players may join in games held nationwide. For example, players who go bowling have competed in games held in Hong Kong and Wenzhou.

Q: Did parents accompany them?

LZ's mother: These players go with the teacher.

Q: Would they share experiences with parents willingly after returning home?

LZ's mother: Absolutely. They have been talkative. They may also share with encountered acquaintances. For example, they would claim that it was too hot. They were too tired to perform normally. They also enjoy any special treatment. They attend an annual 4-day summer camp in Songjiang District in Shanghai.

Q: Is there anything worth mentioning in your mind about the camp?

LZ's mother: Certainly. LZ would tell me anything he could think of. For example, they might fold clothes in the dormitory. The teacher would bathe them and scrub their back. These children are innocent. Children with ID in Hongkou District such as LZ have participated in a variety of activities. They are more sophisticated than those from other districts. Children with ID don't dare go out and depend heavily on their (parents) if they always stay at home.

Q: What are other activities are held in the summer camp?

LZ's father: Physical examination.

LZ's mother: That is another program. LZ tells us everything. These children do not need to take anything to participate in the summer camp. They will be granted clothes and towels from the authorities concerned. The food is also great. They receive better benefits now. Moreover, they also attend classes. LZ, can you talk about the classes available there?

LZ: The etiquette class and the writing class. I could play the role of a journalist or an environmental volunteer. (Proudly shows a certificate of merit) I was selected as a star talent in the training camp.

LZ's mother: LZ wins a certificate of merit every year.

LZ: And Special Olympics activities.

LZ's mother: Which activities?

LZ: Well, supermarket, that is, shopping.

LZ's mother: I see. They are shopping in a simulated supermarket.

LZ: We pay and redeem products.

LZ's mother: They can have a shopping experience via the game. They also learn to spend money and calculate change. Can you do that?

LZ: Well, the teacher would calculate change. 
LZ's mother: Oh, the teacher would help them.

LZ: I have also written articles which have been posted on the walls.

Q: What are they about?

LZ: Environmental protection.

(LZ proactively opens his exercise book.)

LZ's mother: He is showing an article on environmental protection he (wrote).

LZ: I did not want to be a journalist this year. I just wanted to play the role of the group leader. I went to bed on the first night. However, I was asked to write articles the next night. I would not be dismissed until I wrote one. It turned out that the article was wonderful (very proud). The teacher thought highly of it and told me that it would be selected to go into a book. I have already determined the illustrating picture, in which I stood (next to) the bronze statue of Franklin Roosevelt, a former US President.

LZ's mother (cheerfully): He likes to talk about such nonsense.

LZ (angrily): Well, the President.

LZ's mother (echoed): Yes, the President.

Q: Are these things LZ has experienced as a journalist?

LZ's mother: Yes. His article is published with one of his photos on the page. He stood next to the bronze statue of Franklin Roosevelt in the photo.

LZ: He served as President for four terms in succession.

LZ's mother: LZ is famous now. He also enjoys a reputation in square dancing. He told me that he now has fans when dancing at night. He said that I was blessed to have him as a son. That is true (laughed a hearty laugh). He mentioned that we, as a couple, should be proud to be parents to him (clapped her hands and roared with laughter). I am relieved as long as he enjoys doing these things and is happy. LZ likes to dance in public. He enjoys performing on stage (See Fig. 1).

Q: Have you completely supported him participating in Special Olympics activities?

LZ's mother: Of course. We have witnessed LZ's progress. He was not so active before participating in these games. Our friends know that LZ likes dancing. They sent him a pair of boots as a gift after a trip from Xinjiang. He brought them home and told me that he would wear them in his performance. He likes wearing folk (costumes) and performing ethnic and folk dance.

LZ: I am from an ethnic minority.

LZ's mother: LZ joined in a global Special Olympics activity. A party was held for Special Olympics teams all over the world in a hotel in Hongkou District. LZ was thrilled to be there. An actress was there from Inner Mongolia in China or Mongolia.

LZ: Wulan.

LZ's mother: That is correct. Her name is Wulan. She wore a folk costume that night. LZ was excited and took a photo with her.

LZ's mother: (pointing at a photo) This is LZ delivering a speech. This is Mayor Li. LZ regarded him as his godfather and invited him to do rhythmic gymnastics together. I commented that LZ was good at communicating. Mayor Li had participated in a sports meeting in Hongkou District. Other kids had merely stood by and watched. LZ had come forward and taken a photo with him. 


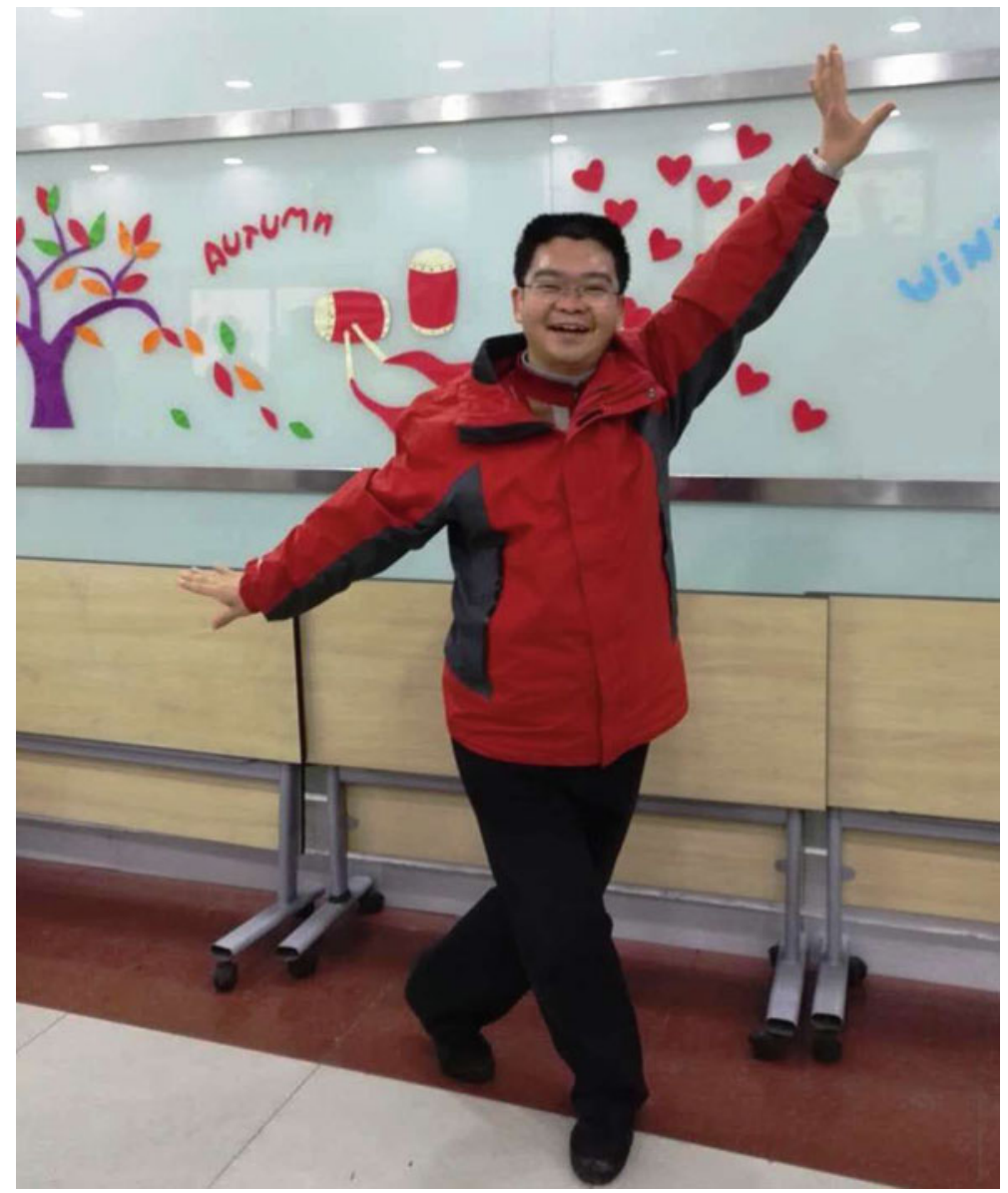

Fig. 1 Mr. LZ likes dancing

Q: Except for LZ's great progress, have you become less burdened now?

LZ's mother: I am relieved now. To tell the truth, I could hardly fall asleep in the past. LZ was a heavy burden on the family. He just stayed at home and got increasingly chubbier. I worried about his future. After all, my husband and I are getting older.

It is hard to go through those 10-plus years. LZ has made progress gradually. At first, he was capable of nothing. I forced him to join in activities. He did not want to play the waist drum and got blisters on his hands. I practiced and also got them. Nonetheless, I insisted on LZ practicing and getting the calluses on his hands.

After mastering the skill, LZ has started to enjoy it. Moreover, he also performed and won honorary titles one by one. No pain, no gain. Encouraged by these achievements, LZ could perform on a larger stage. He was even received by the Mayor and the Deputy Mayor and shook hands with them. LZ was thrilled and shared his 
experiences. He would not even wash his hands and couldn't fall asleep that night. I watched his performance on TV. I had never thought that my son, a disabled person, could be on TV one day. Later on, he was introduced to perform in Beijing and take photos. You can see these (photos) in the Hongkou District CAPIDR. Things are getting better.

LZ's father: I think LZ would not be as outgoing as he is now without these activities. He used to merely stay at home.

LZ's mother: I have gone through the process. I am satisfied that LZ has made such achievements and has been happy. His living conditions have also improved. Previously, he could only earn 250 yuan per month. Now, he has been assigned to a company and receives a statutory minimum wage of 2,190 yuan per month. Thanks to that, LZ can support himself. I think things will be better with an increasingly powerful country. We are really grateful to the government.

LZ is busier than us. On weekdays, he goes to the Sunshine Home before nine o'clock and returns home around three or four o' clock in the afternoon. After dinner, he performs square dancing and returns home at half past eight. Then he washes up, plays on the computer and goes to bed. On Saturday, he practices dancing in Hongkou District Cultural and Sports Training Center for Persons with Intellectual Disabilities. After learning all the moves, he also helps teaching others. He is busy and sweats profusely and takes a bath at home. He also joins in activities and watches The Ultraman on weekend afternoons. He likes watching it.

$\mathrm{Q}$ : Where does LZ perform square dancing in the evening? Who are his partners?

LZ's mother: He basically dances with neighbors in Liangcheng Park.

Q: How did LZ start to perform square dancing? Did he do it to keep fit or out of interest?

LZ's mother: He used to be chubby and stroll around in the neighborhood. As a result, he was encouraged to join in the activity. Just at that time, a person that used to promote Amway products in Liaoning Province stayed in Shanghai and had experience in square dancing. He set up a group to perform.

Q: Does LZ merely like watching The Ultraman or does he buy Ultraman toys?

LZ's mother: He likes collecting Ultraman toys.

Q: In which aspects do you want him to improve?

LZ's mother: I certainly hope that he can develop more interests instead of focusing on one hobby. It may be dull to watch The Ultraman constantly. He has also worked hard every day to play table tennis.

Q: Do you wish for more activities?

LZ's mother: The more, the better. Numerous activities are already being held now.

Q: Will you always support him in participating in all types of activities?

LZ's mother: Absolutely. I will accompany him to join in activities if I am needed. I also regard it as a way of physical exercise. LZ is more famous than us now. When we engage in an activity, I may be asked whether I am his mother. I support him. In turn, he makes me happy (smiles with relief). 


\section{Shouldering Responsibilities at the Sunshine Home}

Q: When did LZ go to the Sunshine Home?

LZ's mother: In 2005. He was among the first batch of students in the Liangcheng Subdistrict Sunshine Home. It was small. The Quyang Subdistrict Sunshine Home has been operating well in the years since then. He was needed there. As a result, he has been transferred to the Quyang Subdistrict Sunshine Home. More activities are held there.

Q: Why did you send LZ to the Sunshine Home?

LZ's mother: The municipal government has established the Sunshine Home as a rehabilitation site for people with ID. These people can learn and exercise. It is a place for people with ID to cultivate themselves.

LZ's father: It also serves as a platform for people with ID to communicate with society.

Q: LZ withdrew from the vocational school in 2001. Why didn't he enroll in the Sunshine Home until 2005?

LZ's mother: The Sunshine Home was not set up in 2001. Shanghai won the bid to host the 2007 Special Olympics World Summer Games in 2002. In 2005, the Sunshine Home was launched as a practical project for the Shanghai Municipal People's Government to be prepared to host the 2007 Special Olympics World Summer Games. That is to say, the Sunshine Home (might) not have been set up if Shanghai had not won the bid to host the (2007 Special Olympics World Summer Games). The Quyang Xincun Subdistrict has been a model in Shanghai. Xiaoping Deng, ${ }^{4}$ a former paramount leader in China, visited Quyang Xincun Subdistrict. After a few years, Jintao $\mathrm{Hu}$, former President of China, and Jinping Xi, current President of China, also visited the subdistrict separately.

LZ's father: The Quyang Xincun Subdistrict has been the first large residential area built in Shanghai and equipped with relatively complete social amenities. Xiaoping Deng used to visit the place. It is still convenient to live here.

Q: Did Quyang Xincun Subdistrict have anything to do with the Sunshine Home at that time?

LZ's: No, it was merely a large subdistrict. Mr. Hu visited Quyang Xincun Subdistrict after the establishment of the Sunshine Home in 2005.

Q: Has LZ been enrolled in the Sunshine Home from 2005 till now?

LZ's mother: Of course. He enrolled in the Liangcheng Subdistrict Sunshine Home in 2005 and transferred to the one in Quyang Subdistrict later (pondering).

LZ: April 8, 2010.

LZ's mother: LZ remembers the date. More activities have been held in the Quyang Subdistrict Sunshine Home. It is also regarded as a sound example among Sunshine Homes in Shanghai.

\footnotetext{
${ }^{4}$ The Quyang Xincun Subdistrict, which is located in Hongkou District, was the first large residential area built in Shanghai since China's economic reform and opening up and matched with relatively complete social amenities. Xiaoping Deng visited families and the farmers' market there in February 1983.
} 
Q: Did LZ suggest that he be transferred?

LZ's mother: Yes. To be honest, the Quyang Subdistrict Sunshine Home has been equipped with more complete facilities.

Q: How did LZ know that the Quyang Subdistrict Sunshine Home was superior?

LZ's father: It was reported in the newspaper. Mr. Hu has also visited the place.

LZ's mother: We read it in the newspaper. Residents in Hongkou District are fully aware of that. The Quyang Subdistrict Sunshine Home has shared the place with a Sunshine Workshop ${ }^{5}$ to involve students in practical operation. I worried that LZ might be inferior in actual operation. He assured me that he wanted to do manual work. He started from the simplest work and aimed to make money. I helped him contact the Quyang Subdistrict Sunshine Home. He was approved to be transferred. After all, he speaks fluently and can play the role of a guide to accompany (visitors) in activities held by the Quyang Subdistrict Sunshine Home.

Q: Can students select a Sunshine Home at will?

LZ's mother: They can only do that in their districts. For example, LZ is registered in Hongkou District. He cannot enroll in the Sunshine Home in Huangpu District. It is free of charge for LZ to go to the Liangcheng Subdistrict Sunshine Home. He is charged 60 yuan per month to be transferred to the Quyang Subdistrict Sunshine Home. Nonetheless, I am willing to pay to let LZ stay at the Quyang Subdistrict Sunshine Home. He can learn more there.

Q: Is the Sunshine Home open from Monday to Friday?

LZ's mother: That is correct. If students are free, they will play the harmonica. Students have established a band and play on Tuesday afternoons. When do you have singing courses?

LZ: Monday morning.

LZ's mother: A variety of activities are held in the Quyang Subdistrict Sunshine Home. Students wear school uniforms and play the harmonica on Tuesdays, try paper cutting on Wednesdays, and dance on Fridays. Being established as a model, the Sunshine Home is also visited by peers at home and foreigners.

LZ: Children from the Sunshine Home can go to the training camp. Those from the base cannot.

LZ's mother: There are certain regulations.

LZ: I am from the Sunshine Home.

LZ's mother: The Sunshine Home and the Sunshine Workshop are different. Students are treated differently in these two institutions. In theory, LZ is a student at

\footnotetext{
${ }^{5}$ The Sunshine Workshop, also named as the Sunshine Base, is formally known as the Sunshine Occupational Rehabilitation Aid Base. According to Shanghai Almanac 2011, it was a practical project for Shanghai Municipal People's Government to create 100 Sunshine Occupational Rehabilitation Aid Bases in 2010. In fact, 170 have completed construction. The base is not a formal labor and employment organization providing occupational rehabilitation aids. It is operated on the basis of "subsidies from the government and enterprises and work of disabled persons" to provide the minimum subsistence allowance for moderately disabled persons. In the Sunshine Base, unemployed disabled persons are gathered together to receive vocational training and work. The Sunshine Workshop, the Sunshine Home, and the Sunshine Psychiatric Garden are called the three Sunshine Institutions.
} 
the Sunshine Home and does not need to work. However, he, together with several other agile students, may be asked to give a hand in busy seasons in the Sunshine Workshop.

Work is regarded as a top priority. Students participate in activities in their spare time. They are busy. They need to prepare programs to participate in joint performances at the district level. They also need to perform in numerous competitions such as the radio calisthenics competition.

Q: Has LZ received subsidies to work in the Sunshine Workshop?

LZ's mother: Sure. LZ likes to work there. He wants to make money (laughs heartily). He is aware of that. He is willing to work hard and seriously.

Q: What does LZ do?

LZ's mother: He makes sponge balls and sponge brushes for a manufacturer in Taiwan. Sponge brushes can be applied to washing cups.

LZ: Commodities.

LZ's mother: He is accomplishing simple tasks such as making labels for Oishi and toothpick wrappers and preparing post sent by the post office ${ }^{6}$ and double-sided tape.

LZ: And posters.

LZ's mother: Did you mean flyers?

LZ: One, two, three, and four. The assembly line.

LZ's mother: They receive small payments to make appropriate handwork. The main point is to involve them in practical operation. They are paid quarterly according to their speed at work. The minimum payment is 60 yuan per quarter. LZ can make over 200 yuan. The best ones may earn 300 or 400 yuan. These students are delighted to work and earn money. They do not care much about the amount.

Q: Does LZ spend the money he earns?

LZ's mother: He earns and spends money as he wants. He saves his money to buy a major commodity in the future.

Q: Can LZ go shopping all by himself?

LZ's mother: He can only do simple calculations.

Q: Has LZ bought you any gifts after participating in activities held in places outside Shanghai?

LZ's mother: LZ merely stays in Shanghai. Some kids may buy toys or local specialties. He will if he goes to other places.

Q: It seems that you are satisfied with how the Sunshine Home and the Sunshine Workshop operate. Is there any aspect they can improve on?

LZ's mother: What is your opinion, LZ?

Q: Is there any shortcoming in the operation of the Sunshine Home?

LZ's mother: LZ likes to go there.

Q: How does LZ get along with his classmates there?

LZ's mother: Are you happy? How do you get along with your classmates?

LZ: Fine.

LZ's mother: He is happy and gets along well with his classmates.

\footnotetext{
${ }^{6}$ Ads and notices printed by the post office. They need to be folded and sealed.
} 
Q: Does LZ have any friends at the Sunshine Home?

LZ: Yes.

LZ's mother: He has a lot of friends. Here is the photo (showing a photo). This is them performing at the TV station.

LZ: Cao.

LZ's mother: Yep, Cao and Shi.

Q: Does LZ have any cousins? Are they close?

LZ's mother: Certainly. It is not hard for LZ to communicate with his cousins. They are polite and close. Some children with ID would be looked down upon and abused and beaten. As a result, they might lose confidence to communicate with others. LZ is confident.

Q: Does LZ contact his cousins proactively?

LZ's mother: Of course. He can communicate with them smoothly in family get-togethers. Of course, they will be less in touch if his cousins get married.

\section{Being Grateful and Letting Nature Take Its Course}

Q: Have you considered the issue of marriage for LZ?

LZ's mother: It seems that LZ has no such (physiological need).

Q: We have noticed that young people with ID also have this kind of physiological need when working at a special school as interns.

LZ's mother: LZ's need is not obvious. I discussed it with my husband a long time ago. Many people at his age may want to find a partner and get married.

Q: Is LZ 30 this year?

LZ's mother: Born in 1983, he is 35 nominally. However, he has no such (need) indeed. We are not avoiding (the issue). In fact, we are both (anxious). On one hand, LZ is with mild ID. It is impossible for any girl in a better physical condition to take a fancy to LZ. On the other hand, LZ, being a man, has to shoulder more responsibilities at home. Even if someone doesn't mind LZ's condition and falls in love with him, can they get along and spend the rest of their lives together? Who will be in charge of money in the family? These issues are real. Consequently, we decided to let nature take its course as long as we can (take care of LZ). LZ also expressed that he just wanted to live with us and not got married. We will start to think about it if LZ wants to. Women performing square dancing with $\mathrm{LZ}$ would like to introduce some girl to LZ frequently. LZ refused and remarked that he should start a career before getting married. He has plans (chortles).

He watches TV and knows about love and affection. We have recruited a great many girls with ID in our art team. Some of them want to get married and some do not. Regarding those getting married, some haven't applied for a Marriage License; some have already divorced; some have been tricked to marry normal people and suffered a lot. Two persons have to be capable of supporting themselves to live together. However, LZ still depends on us. I am in my sixties. I have to provide a 
house and take care of LZ even after he gets married. What if we are too old to take care of him?

LZ's father: It does more harm than good for LZ to get married.

LZ's mother: We have to think about the issue. It is possible that LZ may marry a girl. What if she left after giving birth to a baby? What if the baby was also with ID? I have discussed the issue with several teachers and reached the conclusion that it is better for LZ to live all by himself.

Q: Which preferential policies are enjoyed by LZ?

LZ's father: LZ receives the statutory minimum wage in Shanghai every month.

Q: Is the amount 2,190 yuan?

LZ's mother: LZ is capable of supporting himself. He lets me keep his monthly income of 2,190 yuan as his living expenses. He hardly spends any money.

Q: Is there anything else except the minimum wage?

LZ's mother: That is all. LZ is with mild ID. People with moderate ID or above are identified as the severely disabled and receive state unemployment benefits of about 1,680 yuan now (uncertain facial expression).

LZ's father: Not all people with ID can be assigned to a company. Major companies in Hongkou District have offered a small number of posts. LZ is lucky to get one and be paid without the need to work.

LZ's mother: Of course. A small number of people with mild ID can be assigned to companies now. Regarding the rest, they are covered in the social insurance scheme via the Sunshine Base. Students graduated from Miyun School have mild ID. Currently, any student enrolling in the Sunshine Base can be covered in the social insurance scheme.

Q: LZ both receives income from the Sunshine Base and the statutory minimum wage. Is that correct?

LZ's father: Exactly. It was thought that people with ID assigned to certain companies could work as normal people do and be self-supporting after being trained in the Sunshine Home for a while. In that case, it would reduce the burden on cooperative companies. However, these people fail to get a job. They cannot compete with normal people such as college graduates.

In fact, companies are required to offer certain posts to people with mild ID. These people do simple tasks and get the statutory minimum wage. These companies, which have no other choice, would rather pay the statutory minimum wage to keep people with ID away.

Q: It may be troublesome if these people truly work there, right?

LZ's mother: In comparison, we are lucky to be in Shanghai.

Q: It seems that you are content about efforts made by society and the government to help the disabled. Do you expect more?

LZ's mother: We mainly hope that the disabled can get more help. One day when we are too old to take care of them, they won't be able to support themselves with the current allowance.

LZ's father: We are getting older while LZ is growing up. A company may be mandated by the government to pay LZ for nothing. However, I don't think it is a permanent solution for either the company or the government. Here is the original 
intention of the government. People with mild ID, after being trained for a while, should be more competent to work normally and support themselves. We parents also wish for the same result. However, under the current circumstances, I am pessimistic on this actually being realized.

Q: Do you have any sound ideas?

LZ's father: It is hard to realize them (smiles to ease embarrassment). As a parent, I certainly hope that LZ can fit into society and have an appropriate job to stand on his own feet. However, we are fully aware of LZ's capabilities. He is a slowcoach indeed. It is impossible to act in haste to help him grow. We are content that LZ can receive the statutory minimum wage as the allowance. After all, LZ is not the only person in need in China. We can also take care of him. LZ is carefree.

LZ's mother: Independence is significant. We cannot test him to see whether he can live independently for several months.

Q: LZ is lucky to be your child. We have communicated with parents because of our major. We have found that children's development is greatly impacted by their parents' outlook.

LZ's mother: I think it is a demanding major.

LZ's father: What is your major?

Q: Special Education.

LZ's father: It is indeed challenging.

LZ's mother: It has been a pleasure talking with you. I have never met a person who majored in Special Education before.

Q: Let's just conclude here today. Thank you for your cooperation. We will keep in touch.

LZ's mother: You are welcome. Thank you for your effort.

\section{Interview with Mr. LZ's Teacher}

Interviewee: Teacher

Interviewer and writer: Peifeng Wang

Interview date: January 3, 2017

Interview place: A Subdistrict Sunshine Home in Shanghai

Q: What about LZ's attendance at the Sunshine Home?

Teacher: He attends the Sunshine Home regularly.

Q: What about his performance?

Teacher: LZ is smarter and keener than his classmates. He is more energetic in participating in profitable activities such as artistic performances. On the contrary, he has no passion for routine manual work. Being the class monitor, he should take the lead in sweeping the floor. However, he merely watches others doing it. He may also be just posturing if he is caught by a teacher.

Q: What are LZ's strengths and weaknesses? 
Teacher: He performs poorly in math but is good at recitation. For example, he cannot take 50 yuan to go shopping. He is not capable of telling right from wrong but can play something by ear.

Q: What about LZ's social adaptability?

Teacher: He is tractable and confident and likes to push himself forward. On the whole, he is good at art and literature and can dance to music.

Q: How well do LZ's parents cooperate with teachers?

Teacher: LZ can understand teachers well and explain (teacher's requirements) clearly after returning home.

Q: Which issues may be faced by the Sunshine Home and the Sunshine Base in operation?

Teacher: They are well funded but cover a small area, making it hard to install equipment and launch psychiatric rehabilitation programs. Teachers are underpaid with few benefits and unable to do as well as they wish to. They seem to enjoy the treatment provided for civil servants but actually work as a high-class babysitter. They are under great pressure. On one hand, students have poor memory. They have to be taught the same information repeatedly. On the other hand, students' safety is the top priority. These students may quarrel and fight frequently. Teachers have to handle these issues as quickly as possible. More parents send their children to the Sunshine Home to save trouble. They tend to protect their children and blame the Sunshine Home and teachers for any accidents. As a result, the Sunshine Home must offer courses on emotion management.

Q: Do teachers work fulltime or part time?

Teacher: Fulltime. Teachers are recruited via social recruitment and go to work after being trained. The Quyang Subdistrict Sunshine Home shares a place with the Sunshine Base and the Sunshine Psychiatric Garden. They are called "Three Auspicious Sunshines" jointly and are set as a model in the sector. The Sunshine Home is visited by visitors from home and abroad throughout the year. As a result, full-time teachers are required to receive them.

$\mathrm{Q}$ : What is the source of funds for the "Three Auspicious Sunshines" to maintain normal operation?

Teacher: Funds allocated by the government, subsidies from the DPF and donations from well-wishers in society.

Q: What are sources of work tasks available in the Sunshine Base?

Teacher: We contact enterprises to cooperate and produce products, most of which are giveaways sent by these enterprises to their clients.

\section{Interview with Mr. LZ's Classmate}

Interviewee: $\mathrm{Mr}$. S

Interviewer and writer: Peifeng Wang

Interview date: January 3, 2017

Interview place: A Subdistrict Sunshine Home in Shanghai 
Q: How long have you known LZ?

S (looks at LZ with an inquiring look): Since about 2005.

Q: Do you like LZ?

$\mathrm{S}$ : Sure. He is like my elder brother and a great dancer.

Q: Does he teach you dancing?

$\mathrm{S}$ : He likes helping others. He teaches me to dance and speak Japanese and English.

Q: What about your common hobby?

$\mathrm{S}$ (confused and in thought): Hobby?

LZ (looks at $\mathrm{S}$ and tries to give him a hint): Righteous heroes.

S: Ultraman.

Q: What do you think are LZ's shortcomings?

$\mathrm{S}$ : He is perfect. That is his only shortcoming.

Q: Is LZ liked in the class as the class monitor?

$\mathrm{S}$ : Everyone obeys him. He is clever.

\section{Interview with Mr. LZ}

\section{Interviewee: LZ}

Interviewer and writer: Peifeng Wang

Interview date: January 3, 2017

Interview place: A Subdistrict Sunshine Home in Shanghai

Q: When do you go to the Sunshine Home?

LZ: Sometimes earlier and sometimes later. I return home after three o'clock in the afternoon.

Q: How do you go home? By bus?

LZ: I walk to the Sunshine Home in the morning as exercise and go home by bus in the afternoon.

Q: Do you like going to the Sunshine Home?

LZ: It's fine. It has a sound environment with rich oxygen, just like a fairy tale world.

Q: Do you like the teachers here?

LZ: They are good.

Q: Who is your favorite?

LZ: Ms. Lu. I nicknamed her "Junko Ojika," the heroine in Moero Attack, a Japanese TV Drama.

Q: Why?

LZ: She is pretty and also a fan of Japanese animation.

Q: Which courses are offered at the Sunshine Home?

LZ: A large number of activities are held here. We sing and string beads on Mondays. We play the saxophone and the harmonica on Tuesdays if we do not need to work. On Wednesdays, we participate in activities held jointly by the Sunshine Home and the Shanghai Beijiao High School and learn paper cutting from teachers 
from the Hongkou District Cultural Activities Center. We play diabolo and learn Chinese calligraphy on Thursdays and dance on Fridays.

Q: How do you feel about the food here?

LZ: Chow Mein on Wednesdays is greasy. I like other dishes such as rice cakes and egg fried rice.

Q: Do you participate in activities held at the Hongkou District DPF on weekends?

LZ: Sure.

Q: What do you do at home?

LZ: I watch TV, learn Japanese, ${ }^{7}$ write Chinese characters, ${ }^{8}$ dance, and surf the Internet sometimes.

Q: Do you chat with your parents at home? What do you talk about?

LZ: We talk about the school, dance, and Ultraman (whispered).

Q: Do you help them to do housework?

LZ: Of course. I wash my clothes, clear the table, do the dishes, and sweep the floor.

Q: Which parent do you love more?

LZ: I love both of them.

Q: Which one do you talk to more?

LZ: Mother.

$\mathrm{Q}$ : Which one is stricter with you?

LZ: Both.

Q: When do you start dancing in the evening?

LZ: From seven o'clock to eight o'clock.

$\mathrm{Q}$ : Do you dance every day?

LZ: Yes.

Q: Do you dance with fixed partners?

LZ: We have a team.

Q: Is there an audience?

LZ: People who pass by. The Spring Festival is around the corner. As a result, restaurants are busy.

Q: What do you do after returning home?

LZ: I go over what I have learned and exercise. I work if there are tasks. I am making red envelopes now. Last time, I made bubble stickers. I can both improve my manual dexterity and generate more income.

\section{Observation of Mr. LZ in the Drum Team}

Observation date: 09:00-11:30, November 27, 2016

Observation place: Hongkou District Disabled Persons' Federation, Shanghai

\footnotetext{
${ }^{7} \mathrm{LZ}$ teaches himself Japanese out of interest and can communicate smoothly in Japanese.

${ }^{8} \mathrm{LZ}$ has developed an intense interest in ancient Chinese poems and poets since he was little and he is fond of writing traditional Chinese characters.
} 


\section{Observer and writer: Peifeng Wang}

\begin{tabular}{|c|c|c|}
\hline Time & Activities & Remarks \\
\hline 09:13 & Two formations combined into one & $\begin{array}{l}\text { LZ, being the leader of the waist drum } \\
\text { team, stood by and watched with satisfied } \\
\text { facial expression }\end{array}$ \\
\hline 09:16 & $\begin{array}{l}\text { Two formations were adjusted with } \\
\text { individual members being instructed by } \\
\text { the teacher }\end{array}$ & \\
\hline 09:20 & $\begin{array}{l}\text { LZ joined in the team as the leader to } \\
\text { perform the waist drum program called } \\
\text { Chinese Kung } \mathrm{Fu}\end{array}$ & $\begin{array}{l}\text { LZ was confident and passionate and kept } \\
\text { smiling and nodded in greeting to the } \\
\text { observer from time to time }\end{array}$ \\
\hline 09:24 & $\begin{array}{l}\text { Time-out and the teacher corrected } \\
\text { postures of individual members }\end{array}$ & $\begin{array}{l}\text { LZ put his arm on S's shoulder and } \\
\text { chatted }\end{array}$ \\
\hline 09:25 & $\begin{array}{l}\text { The activity ended and all students took a } \\
\text { break }\end{array}$ & \\
\hline 09:34 & $\begin{array}{l}\text { Performed a group dance called The } \\
\text { Lotus Pool by Moonlight }\end{array}$ & $\begin{array}{l}\text { LZ danced proficiently and elegantly, } \\
\text { winning unanimous praise }\end{array}$ \\
\hline 09:38 & $\begin{array}{l}\text { Performed a group dance called Sunny } \\
\text { Days in September }\end{array}$ & $\begin{array}{l}\text { LZ's moves were in place, with a smile on } \\
\text { his face }\end{array}$ \\
\hline 09:40 & $\begin{array}{l}\text { Time-out and teachers corrected moves of } \\
\text { individual students }\end{array}$ & \\
\hline 09:45 & $\begin{array}{l}\text { The activity ended and all students took a } \\
\text { break }\end{array}$ & $\begin{array}{l}\text { Observation subjects gave a glass of } \\
\text { water to corresponding observers }\end{array}$ \\
\hline 10:00 & Performed Jing Wu martial arts & $\begin{array}{l}\mathrm{LZ} \text { was full of energy and performed } \\
\text { vigorously and robustly }\end{array}$ \\
\hline 10:02 & $\begin{array}{l}\text { The performance was over. The teacher } \\
\text { asked: "What do you think of your } \\
\text { performance?" The teacher corrected } \\
\text { postures of the whole team and instructed } \\
\text { individual students }\end{array}$ & \\
\hline 10:08 & Performed Jing Wu martial arts again & LZ spared no effort all the way \\
\hline 10:10 & $\begin{array}{l}\text { The martial arts ended and students took a } \\
\text { break }\end{array}$ & $\begin{array}{l}\text { LZ sat down and drank some water and } \\
\text { looked around }\end{array}$ \\
\hline 10:20 & Performed the group dance Little Apple & LZ beamed and performed vigorously \\
\hline 10:24 & Performed the group dance Tao Ma Gan & \\
\hline 10:26 & Male solo & $\begin{array}{l}\text { LZ performed robustly with moves in } \\
\text { place; girls watched }\end{array}$ \\
\hline $10: 30$ & Female solo & Boys watched \\
\hline $10: 32$ & The performance was over & All teachers and students went to a bakery \\
\hline 10:40 & The baking activity started & $\begin{array}{l}\text { Students put on gauze masks, hats, gloves } \\
\text { and aprons. LZ was deeply interested and } \\
\text { focused on baking }\end{array}$ \\
\hline $11: 30$ & Took a group photo & \\
\hline
\end{tabular}


(continued)

\begin{tabular}{l|l|l}
\hline Time & Activities & Remarks \\
\hline $11: 40$ & The baking activity ended & $\begin{array}{l}\text { The observation subjects sent baked cakes } \\
\text { to corresponding observers to show } \\
\text { gratitude }\end{array}$ \\
\hline $11: 42$ & Completed observation. & \\
\hline
\end{tabular}

\title{
Observation of Mr. LZ at the Sunshine Home
}

\author{
Observation date: 09:00-14:30, January 3, 2017
}

Observation place: A Subdistrict Sunshine Home in Shanghai

Observer and writer: Peifeng Wang

The Spring Festival is close. Students at the Sunshine Home mainly make red envelopes for enterprises and public institutions.

\begin{tabular}{|c|c|c|}
\hline Time & Tasks & Remarks \\
\hline 09:00 & $\begin{array}{l}\text { Made red envelopes (printed with } \\
\text { Chinese characters: " } 2017 \text { exercising and } \\
\text { developing a healthy lifestyle"); packed } \\
\text { three red envelopes in one pack and } \\
\text { bundled up every } 25 \text { packs with rubber } \\
\text { bands }\end{array}$ & $\begin{array}{l}\text { LZ was skilled and efficient. He was } \\
\text { energetic with a smile on his face, } \\
\text { chatting with students next to him and } \\
\text { working simultaneously. He nodded in } \\
\text { greeting to the observer from time to time } \\
\text { and stood up and looked around }\end{array}$ \\
\hline 09:55 & $\begin{array}{l}\text { LZ stood up and carried red envelopes to } \\
\text { another classroom }\end{array}$ & Trotting \\
\hline 09:57 & LZ continued packing red envelopes & $\begin{array}{l}\text { Completed packs piled in a jumble. A } \\
\text { classmate helped put them in order and } \\
\text { LZ thanks the classmate }\end{array}$ \\
\hline $10: 30$ & Took a break and drank some water & $\begin{array}{l}\text { LZ showed the observer where the water } \\
\text { dispenser was and gave a glass of water to } \\
\text { the observer }\end{array}$ \\
\hline 10:40 & $\begin{array}{l}\text { LZ took the observer to watch a } \\
\text { saxophone performance and introduced } \\
\text { members in the band to the observer one } \\
\text { by one }\end{array}$ & $\begin{array}{l}\text { He expressed pride not only in words but } \\
\text { also in his expressions }\end{array}$ \\
\hline $11: 50$ & Lunch break & \\
\hline $12: 40$ & $\begin{array}{l}\text { Continued folding and packing red } \\
\text { envelopes }\end{array}$ & $\begin{array}{l}\text { LZ started to feel tired and slowed down } \\
\text { in work. A while later, he pulled himself } \\
\text { together and accelerated packin }\end{array}$ \\
\hline $14: 30$ & School was over & $\begin{array}{l}\text { Handed in packs and the teacher counted } \\
\text { the quantity. LZ completed the most, } \\
\text { reaching } 336\end{array}$ \\
\hline
\end{tabular}


Open Access This chapter is licensed under the terms of the Creative Commons AttributionNonCommercial-NoDerivatives 4.0 International License (http://creativecommons.org/licenses/bync-nd/4.0/), which permits any noncommercial use, sharing, distribution and reproduction in any medium or format, as long as you give appropriate credit to the original author(s) and the source, provide a link to the Creative Commons license and indicate if you modified the licensed material. You do not have permission under this license to share adapted material derived from this chapter or parts of it.

The images or other third party material in this chapter are included in the chapter's Creative Commons license, unless indicated otherwise in a credit line to the material. If material is not included in the chapter's Creative Commons license and your intended use is not permitted by statutory regulation or exceeds the permitted use, you will need to obtain permission directly from the copyright holder.

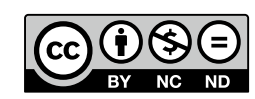

